\title{
AÇÕES AFIRMATIVAS: A POLÊMICA EM TORNO DA CONSTITUCIONALIDADE DA POLÍTICA DE COTAS PARA NEGROS NO ENSINO SUPERIOR PÚBLICO BRASILEIRO
}

\author{
AFFIRMATIVE ACTIONS: THE CONTROVERSY OVER THE \\ CONSTITUTIONALITY OF QUOTA POLICY FOR BLACK STUDENTS IN \\ BRAZILIAN HIGHER EDUCATION
}

\author{
Fabrício Bittencourt da Cruz ${ }^{1}$ \\ Fernanda Van Kan ${ }^{2}$
}

Envio: 30 set. 2011.

Aceitação: $16 \mathrm{fev} .2012$.

\section{RESUMO}

O presente trabalho, desenvolvido sob o método dedutivo, trata das ações afirmativas como meio de concretização da igualdade material, em especial da polêmica em torno da constitucionalidade da política de cotas para negros no ensino superior público brasileiro. Analisa o princípio e o direito fundamental à igualdade; o contexto, a definição e o desenvolvimento das ações afirmativas, principalmente nos Estados Unidos e no Brasil, para a partir daí tratar da política de cotas raciais, trazendo algumas manifestações da Arguição de Descumprimento de Preceito Fundamental (ADPF) 186, que tramita no Supremo Tribunal Federal, ainda pendente de julgamento. O objetivo deste trabalho é incentivar o debate, apresentando argumentos favoráveis e desfavoráveis à reserva de vagas para negros nos bancos universitários. Sob o manto do postulado da proporcionalidade enquanto marco teórico, analisa a constitucionalidade da política de cotas raciais no ensino superior público brasileiro.

Palavras-chave: Ação afirmativa. Igualdade. Cotas raciais. Proporcionalidade. Constitucionalidade.

\begin{abstract}
This paper presents a study about affirmative actions used as instruments to improve material equality. Particular attention is given to the controversy about the constitutionality of the policy of quotas in public Brazilian higher education. The study was developed according to the deductive method. The paper analysis the principles and fundamental rights to equality, the context, definition and the
\end{abstract}

\footnotetext{
${ }^{1}$ Magistrado federal; professor assistente, Departamento de Direito do Estado, Universidade Estadual de Ponta Grossa (UEPG); professor da Escola da Magistratura Federal no Paraná; professor da Escola da Magistratura Estadual no Paraná; mestre em direito pela PUC-PR; doutorando pela Universidade Católica de Santa Fé - Argentina. Email: <fabriciobittcruz@gmail.com>

2 Bacharel em direito pela UEPG. Email: <fervankan@yahoo.com.br.>
} 
development of affirmative actions, especially in the USA and in Brazil. After this, the paper focuses on the policy of racial quotas and presents some arguments exposed in the ADPF 168 - that awaits judgment at the Brazilian Supreme Court. The aim of the article is to encourage the debate, presenting arguments for and against the affirmative actions in public universities. Under the principle of proportionality, the text analyses the constitutionality of racial quotas in public Brazilian higher education.

Keywords: Affirmative action. Equality. Racial quotas. Proportionality. Constitutionality.

O contexto do Brasil Imperial foi de escravidão, em que o escravo era a principal fonte de trabalho produtivo e estava destinado a produzir, em grandes quantidades e em grandes fazendas, matéria-prima para exportação. O escravo era considerado apenas uma mercadoria, uma associação de capital e trabalho (PEREGALLI, 1988). O regime escravocrata durou três séculos e meio, período no qual o Brasil importou quatro milhões de negros africanos, ou $40 \%$ do total importado pelas Américas. A abolição da escravatura ocorreu somente em 13 de maio de 1888, por ocasião da Lei Áurea. Não se desconhece que o 13 de maio foi colocado em descrença pelo Movimento Negro, considerado uma data "branca", comemorativa de um gesto de suposta "benevolência" (TOLEDO, 1996).

Com a assinatura da Lei Áurea, os escravos alcançaram a liberdade formal, pois no período posterior à abolição não foram criadas ações que possibilitassem aos afro-brasileiros a superação das precárias condições de vida, resultado da submissão ao regime de trabalho escravo. Ademais, a entrada em grande escala de imigrantes europeus proporcionou, em algumas regiões, a redução das chances de ingresso e de competição dos afro-brasileiros no emergente mercado de trabalho urbano (SISS, 2003).

Em relação ao acesso ao processo educacional, a exclusão dos negros é histórica, o que se percebe pela Lei 01 , de 4 de janeiro de 1837, no seu artigo 3. ${ }^{\circ}$, que prescrevia que os escravos e os "pretos" africanos, ainda que livres ou libertos, eram proibidos de frequentar as escolas públicas (SISS, 2003). Em 1934, o político e ativista social Abdias Nascimento solicitou ao governo do Rio de Janeiro medidas para garantir o acesso de negros no ensino público, mediante reserva de vagas. Apesar disso, somente na década de 1990 a luta pela inclusão de negros na educação formal realmente invadiu o poder público com reivindicações contra o racismo (BERTÚLIO, 2009). Dez anos mais tarde é que surgiram as primeiras proposições de ações afirmativas com base na raça dos indivíduos para diversos ramos nas relações sociais. Na Biblioteca Central da Universidade de Brasília (UnB), em 1999, ocorreu importante discussão sobre as políticas de cotas raciais para a universidade brasileira. $\mathrm{O}$ tema foi discutido e uma proposta foi aprovada em 2003, tendo sido a UnB a primeira a aprovar as cotas para índios e negros após quase cem anos de ensino superior público no Brasil (CARVALHO, 2006).

O tema é polêmico, tanto que o Estatuto da Igualdade Racial (Lei 12.288/2010), o qual reúne um conjunto de ações e medidas especiais que visam a garantir direitos fundamentais à população afro-brasileira e traz considerações sobre discriminação racial ou etnorracial, desigualdade racial, desigualdade de gênero e raça, população negra, políticas públicas e ações afirmativas, foi sancionado sem fazer menção alguma ao sistema de cotas raciais para ingresso no ensino superior público, apesar de, inicialmente, o Projeto de Lei 3.198/2000 ter incluído tal proposta, a fim de minimizar os efeitos nocivos do preconceito racial e efetivar uma igualdade de oportunidades.

Além disso, o Partido Democratas (DEM) ajuizou, em julho de 2009, a Arguição de Descumprimento de Preceito Fundamental (ADPF) 186 requerendo a declaração de inconstitucionalidade de atos administrativos da Universidade de Brasília que instituíram a política de cotas raciais em seus vestibulares, alegando violação de diversos princípios constitucionais. 
Neste contexto, insere-se o trabalho ora apresentado, que tem por objeto a análise da constitucionalidade da política de cotas para negros no ensino superior público brasileiro. Aborda-se, inicialmente, o direito fundamental à igualdade, correlacionando-o com o princípio da não discriminação, o direito à diferença, a igualdade material, as ações afirmativas e a democracia. Em um segundo momento, são tecidas considerações a respeito do conceito, da origem e dos objetivos das ações afirmativas, especialmente nos Estados Unidos. Em seguida, trata-se especificamente do debate a respeito da constitucionalidade da política de cotas para negros em universidades públicas brasileiras. A conclusão é atingida por intermédio da aplicação do postulado da proporcionalidade à questão central deste estudo.

\section{O direito fundamental à igualdade}

A Constituição de 1988 foi promulgada com uma "perspectiva moderna e abrangente dos direitos individuais e coletivos, dos direitos sociais dos trabalhadores, da nacionalidade, dos direitos políticos e dos partidos políticos" (SILVA, 2010, p. 89). Ela apresenta basicamente cinco grandes grupos de direitos fundamentais: direitos individuais (art. 5. ${ }^{\circ}$ ), direitos à nacionalidade (art. 12), direitos políticos (arts. 14-17), direitos sociais (arts. 6. ${ }^{\circ}, 193$ e ss.) e direitos coletivos (art. 5. ${ }^{\circ}$ ).

$\mathrm{O}$ direito fundamental à igualdade está previsto no artigo $5 .^{\circ}$, caput e inciso I, da Constituição Federal. É, segundo classificação do constitucionalista português Canotilho (apud SILVA, 2010), um princípio jurídico-constitucional, ou seja, um princípio constitucional geral informador da ordem jurídica nacional decorrente das declarações de direitos e, segundo o professor e advogado Celso Antônio Bandeira de Mello, "o maior dos princípios garantidores dos direitos individuais" (BANDEIRA DE MELLO, 2004, p. 45). Para a estudiosa Vera Lúcia Carapeto Raposo (2004), ele representa um princípio estruturante dos sistemas constitucionais dos Estados democráticos de direito.

Ao longo da história, a igualdade nem sempre foi um valor reconhecido e realmente efetivado nas sociedades diante dos privilégios concedidos a certas classes. Porém, antigas escolas de pensamento já repeliam a desigualdade e tentavam disseminar a ideia de igualdade substancial (GOMES, 2001).

No século XVIII, houve sensível desenvolvimento do tema da igualdade no plano jurídico, resultando em sua inclusão no rol dos direitos fundamentais de importantes declarações (a norte-americana Declaração de Independência, de 4 de julho de 1776, e a francesa Declaração dos Direitos do Homem e do Cidadão, de 26 de agosto de 1789). O princípio da igualdade também foi incluído nos textos constitucionais de vários países até metade do século XIX, quando começou a entrar em crise o modelo liberal (MENEZES, 2001).

Tais declarações, reveladas em termos liberais, traziam em seus enunciados a ideia da igualdade formal perante a lei geral e abstrata, com o objetivo de estabelecer idêntico tratamento jurídico para todos. A expressão "todos os homens são iguais" foi compreendida como um valor absoluto, sem levar em consideração as reais desigualdades e as condições de cada indivíduo. Considerava-se que todos os indivíduos usufruíam das mesmas condições de vida, não eram analisadas as condições específicas de cada pessoa. Paradoxalmente, ambas as declarações surgiram ao mesmo tempo em que franceses e norte-americanos escravizavam grande parte da população negra mundial, pois a escravidão foi abolida nos Estados Unidos apenas em 1863 e a França manteve suas colônias até 1962 (MOEHLECKE, 2004).

Sob a perspectiva da igualdade material, "surgiram diversas políticas sociais públicas ou privadas de apoio e de promoção de determinados grupos socialmente fragilizados" (GOMES, 2001, p. 5), denominadas ações afirmativas (ou discriminação positiva). São políticas sociais que pretendem a efetiva concretização da igualdade por intermédio de instrumentos de combate à discriminação: o indivíduo não é mais considerado abstrata e genericamente igual a todos, mas "especificado considerando-se categorizações relativas a gênero, idade, etnia, raça, etc." (PIOVESAN apud GOMES, 2001, p. 5).

Para a professora Maria Glória Garcia (2005), a igualdade material é construída, diferentemente da igualdade formal, que vem de uma realidade preestabelecida sem levar em conta as desigualdades empíricas. Sob o prisma da igualdade material, admitem-se discriminações positivas quando desigualdades 
atuais marginalizam determinados grupos em virtude de atitudes tomadas no passado e:

Aquilo que caracteriza a discriminação positiva é: a) o modo da sua atuação, isto é, de seleção de pessoas, na medida em que compagina critérios de mérito com a pertença a determinados grupos; $b$ ) os efeitos, pois acaba por prejudicar indivíduos não pertencentes ao referido grupo, os quais frequentemente iniciam um movimento de protesto, visto se considerarem lesados, já que não sentem o dever moral ou jurídico de "pagar" individualmente a discriminação sofrida por outros indivíduos. [...] A discriminação positiva representa não apenas um inovador entendimento do princípio da igualdade, mas toda uma nova concepção de justiça. (RAPOSO, 2004, p. 307).

Além do direito à igualdade enquanto princípio fundamental, a Constituição Federal inclui o princípio da não discriminação, no seu artigo $5 .^{\circ}$, incisos XLI e XLII, proibindo o preconceito de origem, cor e raça e a discriminação e repudiando o racismo nas relações internacionais. O jurista José Afonso da Silva (2010), especialista em direito constitucional, afirma que a Constituição reconhece que o preconceito de origem, raça, e cor, especialmente contra negros, não está ausente nas relações sociais brasileiras e que "disfarçadamente, ou, não raro, ostensivamente, pessoas negras sofrem discriminação até mesmo nas relações com entidades públicas" (SILVA, 2010, p. 224).

Entretanto, o princípio da não discriminação não rechaça todas as formas de discriminação, pois se sabe que existem diferenciações baseadas em critérios legítimos. Às vezes, é necessário discriminar, "pois está bem claro hoje que tratar como igual a sujeitos que econômica e socialmente estão em desvantagem, não é outra coisa senão uma ulterior forma de desigualdade e de injustiça" (SILVA, 2010, p. 219-20). São discriminações necessárias, pois:

Perante um tratamento formalmente igual emerge imediatamente uma presunção de constitucionalidade. Mas pode suceder que assim não seja, que o trato formalmente igual seja inconstitucional, sendo ao invés constitucional um tratamento formalmente desigual. (RAPOSO, 2004, p. 249).

Celso Antônio Bandeira de Mello (2004) expõe três questões que, segundo entende, não ferem o princípio da isonomia. A primeira delas diz respeito ao critério escolhido como fator discriminatório, que pode ser qualquer um residente nas coisas, pessoas ou situações. O segundo refere-se à relação lógica, a justificativa racional entre o critério discriminatório (gênero, raça, etc.) e a desigualdade dele consequente, resultando no tratamento jurídico diferenciado, pois os elementos sexo, raça, credo religioso etc. não podem gerar, por si sós, discriminação. A terceira questão a ser verificada é a harmonia dos interesses do ordenamento jurídico, em especial os constitucionais, com a relação estabelecida entre o fator discriminatório e a desigualdade acolhida, propulsora do tratamento jurídico diferenciado.

No caso da política de cotas para negros no ensino superior brasileiro é possível afirmar que as cotas estão dentro do primeiro critério. A lógica do segundo critério se estabelece diante das desigualdades observadas racial, social, econômica e culturalmente e no meio universitário, fruto do passado de escravidão e do preconceito. $\mathrm{E}$ a constitucionalidade, terceiro critério, também se verifica, pois a diminuição das desigualdades sociais e regionais constitui um dos objetivos da Constituição Brasileira em seu artigo $3^{\circ}$, inciso III, e, além disso, as cotas estão em consonância com o princípio da igualdade, da não discriminação, da dignidade da pessoa humana e da proporcionalidade.

Segundo a professora Carmen Lúcia Antunes Rocha, também ministra do Supremo Tribunal Federal, os negros, marginalizados pela raça, entre outros grupos minoritários, continuam no vácuo jurídico, sem ter acesso a iguais oportunidades mínimas de trabalho, participação política, cidadania participativa, mesmo com a garantia constitucional da dignidade da pessoa humana, pois são deixados à margem da sociedade em aspectos culturais, sociais e econômicos (ROCHA apud GOMES, 2001). E o Brasil, em relação à África do Sul e aos Estados Unidos, é o país que apresenta as mais flagrantes desigualdades raciais, pois é o que menos avançou na implantação de programas de garantia do exercício da cidadania e de promoção social. Além disso, é ineficaz no cumprimento de pena por condenações que criminalizam discriminações baseadas em cor, raça e sexo. Tem-se, dessa forma, um apartheid informal (GOMES, 2001).

De acordo com Joaquim Benedito Barbosa Gomes (2001), atual ministro do Supremo Tribunal 
Federal, o princípio jurídico-filosófico da igualdade (CF, art. 5. ${ }^{\circ}$, caput e inciso I) é um dos pilares da democracia moderna e elemento essencial da noção de justiça. Constitui-se em um dos princípios do Estado democrático de direito, cuja principal tarefa é a superação das desigualdades sociais e regionais e a realização da justiça social (SILVA, 2010).

A sociedade fraterna, pluralista e sem preconceitos de nosso texto constitucional só será possível com o reconhecimento e o fortalecimento dos grupos minoritários.

A política de cotas, uma das modalidades de ação afirmativa, revela-se instrumento promotor de cidadania (PAULA, 2004), viabilizando a concretização da igualdade material e, consequentemente, o fortalecimento do Estado democrático de direito.

\section{Ações afirmativas}

A expressão affirmative action surgiu nos Estados Unidos (SILVA FILHO, 2009). Contudo, as primeiras ações oficiais de discriminação positiva surgiram na Índia, na década de 1940, com o nome de medidas afirmativas, as quais tinham a finalidade de colocar no parlamento indiano representantes das castas consideradas inferiores (VILAS-BOAS apud SILVA FILHO, 2009). Segundo José Jorge de Carvalho (2006), um estudioso do tema, o criador do sistema de cotas foi o intelectual indiano Bhimrao Ramji Ambedkar, líder dos dalits, os intocáveis, que conseguiu inserir na Constituição da Índia, em 1948, cotas para eles e para os grupos tribais nas instituições de ensino e no serviço público, como modo de compensar milênios de exclusão e desigualdade.

Thomas Sowell (apud JENSEN, 2010), crítico social americano, também é partidário da ideia de que a Índia tem ações afirmativas há mais tempo que qualquer outro país, desde antes de sua independência. O juiz federal Oscar Valente Cardoso (2010) igualmente menciona que a ação afirmativa surgiu na Índia, como um modo de minimizar as desigualdades impostas pelo sistema de castas, mas que teve grande repercussão quando de sua implementação nos Estados Unidos para diminuir o racismo existente no país, em especial contra os negros.

Nos Estados Unidos, as ações afirmativas tiveram grande repercussão. Entretanto, segundo o professor Thomas E. Weisskopf (apud SILVÉRIO,
2006) a base constitucional das ações afirmativas é mais sólida na Índia que nos Estados Unidos da América. Neste país, elas iniciaram nos anos de 1960, na administração do presidente Lyndon Johnson, em virtude do movimento dos afro-americanos na década anterior.

John David Skrentny e Paul Singer (apud JENSEN, 2010) possuem entendimento diverso. Para eles, os primeiros passos das políticas de ações afirmativas foram dados em 1935, nos Estados Unidos da América, com a criação da Lei das Relações de Trabalho Nacionais (The 1935 National Labor Relations Act), que visava combater a discriminação em relação aos trabalhadores sindicalizados, reparar situações de violação legal ou injustiças e também prevenir tratamentos discriminatórios. Se, por exemplo, um empregador discriminasse sindicalistas ou operários sindicalizados, deveria ser utilizada uma ação afirmativa que devolvesse à vítima a posição que ocuparia se não tivesse sido prejudicada em virtude da discriminação.

$\mathrm{Na}$ verdade, o conceito de affirmative action é proveniente dos Estados Unidos. Neste país, as ações afirmativas surgiram por iniciativa do Poder Executivo, sendo que o presidente John F. Kennedy foi o primeiro a utilizar a expressão, em 1961, objetivando ampliar a igualdade de oportunidades para as minorias no mercado de trabalho (MENEZES, 2001). A expressão affirmative action apareceu pela primeira vez na Executive Order (Decreto Executivo) 10.925, de iniciativa do presidente John Kennedy (JENSEN, 2010), que também criou uma Comissão para a Igualdade de Oportunidades de Emprego com a finalidade de combater a segregação estatal, a discriminação em relação a qualquer candidato a emprego ou empregado com base em raça, credo, cor ou origem nacional, assim aumentando as oportunidades de trabalho para aqueles que até então eram discriminados (CARDOSO, 2010).

Com o mesmo objetivo de Kennedy, em 1964 o presidente Lyndon B. Johnson deu continuidade ao projeto legislativo Civil Rights Act, que proibia a segregação dos negros e, em 1965, o Voting Rights Act garantiu aos negros o direito de votar e de serem votados. Naquele mesmo ano, editou-se a Executive Order 11.246, que estabeleceu, como condições à contratação com o governo federal, a cessação de práticas discriminatórias, e o estabelecimento de 
medidas efetivas em prol de minorias étnicas e raciais (MENEZES, 2001).

Segundo Oscar Valente Cardoso (2010), a Executive Order 8.802, de 25 de junho de 1941, foi o embrião das ações afirmativas nos Estados Unidos. Esta Executive Order, conhecida como Fair Emplyoyment Act, proibia a discriminação de negros na seleção de pessoas para trabalhar em órgãos governamentais relativos à defesa nacional. Posteriormente, foram editadas as Executive Orders 9.980 e 9.981 , de 1948, pelo presidente Harry S.Truman, proibindo a discriminação por raça, cor, religião, nacionalidade: a primeira era dirigida ao serviço público federal e a segunda, às Forças Armadas. Outras resoluções com a mesma orientação foram criadas, como a 10.210, em 1951, e a 10.308, em 1951. Entretanto, somente com a Executive Order 11.246, do presidente Lyndon Johnson, em 1965, adotou-se uma posição mais ativa em relação às igualdades de oportunidade e a redução de desigualdades. Ela prescrevia que a política dos Estados Unidos da América deveria possibilitar iguais oportunidades no serviço público federal para todas as pessoas, sem discriminação por raça, religião, cor ou nacionalidade, e de emprego, por meio de um programa positivo e contínuo.

Em 1972, o então presidente Richard Nixon sancionou a Lei de Oportunidade Igual no Emprego (Equal Employment Opportuniy Act), que estabelecia metas e a necessidade de criação de projetos nacionais e regionais que garantissem iguais oportunidades de emprego por parte dos governos estaduais e locais e das instituições educacionais. Por isso, as escolas e universidades norte-americanas começaram a reservar cotas em seus processos de admissão de alunos. Isso foi possível e teve fundamento na Constituição Americana em razão da sua 13. ${ }^{a}$ Emenda, que aboliu a escravidão; da $14 .^{\text {a }}$ Emenda, que garantiu a equal protection clause; e da $15 .^{\mathrm{a}}$, que vedou a discriminação racial no direito eleitoral de voto (CARDOSO, 2010).

Segundo Gomes (2001), a mais antiga e talvez, mais eficaz modalidade de ação afirmativa foi instituída com a Executive Order 11.246/1965, pelo presidente Lyndon Johnson. A administração pública pretendia firmar contratos com empregadores privados sob a condição de que eles empregassem minorias, oferecendo-lhes os mesmos benefícios na carreira em relação aos outros empregados, a fim de reduzir as desigualdades raciais, sexuais, sociais etc.

As ações afirmativas são um conjunto de políticas públicas ou privadas, fundamentadas na perspectiva da igualdade material, e adotadas com o fim de combater todos os tipos de discriminação e corrigir os quadros de desigualdade social presentes em grupos minoritários como resultantes de discriminação passada e/ou ainda atual (GOMES, 2001). Por isso, não podem ser vistas apenas como uma única modalidade: a política de cotas.

As medidas de discriminação positiva tiveram como primeiro objetivo o combate à discriminação racial e, com o passar do tempo, começaram a ser utilizadas também no combate a discriminações de gênero e em relação a outros grupos étnicos. Por isso, o conceito de ação afirmativa inicialmente era o conjunto de medidas do ponto de vista racial, visando a beneficiar minorias raciais em situação de desvantagem social (RIOS).

O objetivo dessas medidas é "eliminar as barreiras artificiais e invisíveis que obstaculizam o acesso de negros e mulheres qualificados a posições de poder e prestígio, limitando-lhes o crescimento e o progresso individual" (GOMES, 2001, p. 48). Essas barreiras, que dificultam a devida representação e a ascensão dos negros na estrutura social e no acesso à educação superior, devem ser superadas.

O primeiro litígio que tratava de programa preferencial de negros em uma instituição de ensino superior a ser julgado nos Estados Unidos foi o caso Regents of the University of California v. Bakke, em 1978. O programa preferencial de admissão da Faculdade de Medicina da Universidade de Califórnia em Davis reservava $16 \%$ das vagas do curso de medicina a minorias, restando $84 \%$ para competição entre as pessoas não classificadas como minorias, em que estas também poderiam participar. Alan Bakke, concorrente das vagas não destinadas às minorias, moveu ação contra a universidade. Na sua decisão, o juiz Lewis Powell entendeu que a redução dos efeitos da discriminação do passado constituía um objetivo governamental imperativo e reconheceu a legitimidade dos programas de ação afirmativa e do fator raça como elemento favorável (plus-factor) no processo de admissão de alunos no ensino superior. Contudo, 
anulou a decisão da universidade por entender que a instituição não detinha competência para instituir política de preferência (GOMES, 2001).

Rios considera que no direito norte-americano há cinco argumentos favoráveis às ações afirmativas que, sob sua óptica, podem ser utilizados para as ações afirmativas em geral: o combate aos efeitos presentes da discriminação passada; a promoção da diversidade; a natureza compensatória ou reparatória das ações afirmativas; a criação de modelos positivos para os estudantes e às populações minoritárias; e a provisão de melhores serviços a comunidades minoritárias. Por outro lado, aponta três objeções: necessidade da observância do mérito e consequente injustiça dos prejuízos à população branca; tensão entre um modelo de proteção individual ou grupal dos direitos, gravidade de algumas modalidades de ação afirmativa (especialmente as cotas) e o caráter prejudicial à população negra; reforço dos estigmas e preconceitos dele decorrentes.

Em relação à natureza compensatória ou reparatória das medidas, elas seriam um modo de remediar os prejuízos dos erros do passado voltados contra certos grupos. As críticas em torno deste argumento estão no fato de beneficiar indivíduos que não foram (diretamente) vítimas de discriminação, na imposição de encargos a quem não se envolveu em práticas discriminatórias, e na medida da compensação devida a cada indivíduo discriminado. $\mathrm{Na}$ verdade, a ação afirmativa considera um grupo de pessoas e o objetivo é ascender o status do grupo (RIOS, 2011).

Outro argumento muito utilizado para derrubar as medidas de ação afirmativa é a chamada racialização. Ante a inexistência de raças, as políticas de ações afirmativas estariam promovendo a segregação racial. Entretanto, quando se fala em discriminação racial o "que está em jogo não são as raças do ponto de vista biológico, mas a racialização construída como representação social que gera desigualdades crônicas e sistemáticas" (CARVALHO, 2006, p. 106). Além disso, as cotas, por exemplo, não separam turmas de alunos negros e turmas de alunos não negros na universidade. Importante refletir trecho da obra de Ronald Dworkin:

Portanto, é a pior incompreensão possível supor que os programas de ação afirmativa têm como intuito produzir uma América balcanizada, dividida em subnações raciais e étnicas. Eles usam medidas mais vigorosas porque as mais suaves fracassarão, mas seu objetivo final é diminuir, não aumentar a importância da raça na vida social e profissional norte-americana. (DWORKIN, 2000, p. 439).

Também é importante fixar que as ações afirmativas (discriminação positiva) constituem medidas especiais e temporárias que objetivam acelerar o processo de igualdade material. Tão logo atingido o objetivo visado, devem ser abandonadas.

Para o professor Jocélio Teles dos Santos (apud BRANDÃO, 2005), doutor em antropologia, um dos primeiros apontamentos a respeito do histórico evolutivo das ações afirmativas no Brasil ocorreu em 1968, quando os técnicos do Ministério do Trabalho e do Tribunal Superior do Trabalho propunham a aprovação de uma lei que obrigasse as empresas privadas a manterem um percentual mínimo de empregados não brancos. Há, contudo, entendimento de que a Consolidação das Leis do Trabalho, de 1943, já trazia dois artigos com medidas afirmativas - o artigo 354, que prevê uma cota de dois terços de brasileiros para empregados de empresas individuais ou coletivas, e o artigo 323-A, que prevê políticas para desigualdade entre homens e mulheres.

A Constituição Federal de 1988 contém vários dispositivos visando a efetivar a igualdade material, e por meio deles se permite a busca da superação de quadros de discriminação e desigualdade com medidas compensatórias diferenciadas. Pode-se dizer que a Constituição Federal legitimou definitivamente a discriminação positiva, pois foi a partir da década de 1990 que o tema começou a ganhar visibilidade, especialmente no que diz respeito às cotas (JENSEN, 2010).

O Brasil é conhecido como o país da democracia racial, o que prejudicou em muito o avanço na criação de políticas de ações afirmativas em favor de grupos minoritários sub-representados. Por isso, a recepção desse instituto não foi (e ainda não é) muito cordial, principalmente em relação à política de cotas raciais. Basta que seja mencionado o fato de o Estatuto de Igualdade Racial, a Lei 12.288, sancionada em 20 de julho de 2011, não conter menção alguma ao sistema de cotas.

A miscigenação do Brasil e a ideia de que não houve uma segregação institucionalizada dos negros após a abolição são fatores que contribuíram para a 
construção do mito da democracia racial: um país repleto de raças e sem preconceitos. Na verdade, ninguém admitia o preconceito e a discriminação, criando o que se chamou de racismo à brasileira, um racismo extremamente velado, porém "tão crônico, abrangente e consistente, que se reproduz em todas as áreas da vida social, e também no interior da instituição universitária" (CARVALHO, 2006, p. 12).

Depois da abolição, alguns escravos passaram a assalariados ou meeiros, arrendadores, trabalhando com a agricultura para a subsistência (ANDRADE apud JENSEN, 2010), enquanto outros ficaram em condições precárias, sem trabalho, o que acabou por agravar a condição socioeconômica dos ex-escravos e de seus descendentes. A condição precária, de miserabilidade social, pela qual passavam foi propícia para que os ex-escravos entrassem no mundo da ilicitude e passassem a ser reprimidos pelo direito penal (BASTIDE; FERNANDES apud JENSEN, 2010).

Entretanto, o grande movimento que trouxe à tona na esfera jurídica e política a questão do racismo, da desigualdade racial e das ações afirmativas

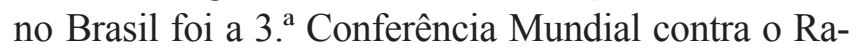
cismo, a Discriminação Racial, a Xenofobia e Formas Correlatas de Discriminação, realizada em Durban, na África do Sul, em setembro de 2001 (BERTÚLIO, 2009). Esta conferência foi um evento notório, porquanto houve o reconhecimento da desigualdade racial brasileira, desmascarando o país da democracia racial e recomendando-se a implementação de cotas raciais pelas universidades públicas brasileiras, com vistas à expansão e o acesso ao ensino superior para os negros (JENSEN, 2010).

\section{Sistema de cotas para negros no ensino su- perior público brasileiro: A Constituciona- lidade da Medida}

As cotas são consideradas a mais radical modalidade de ação afirmativa e, por isso, grande número de países tem-lhe oposto forte resistência, como é o caso do Brasil, com a interposição da Arguição de Descumprimento de Preceito Fundamental 186. Segundo Vera Lúcia Carapeto Raposo, elas são o último instrumento a se utilizar, sendo "restritas a conjunturas em que outras formas de discriminação positiva potencialmente utilizáveis não produziriam resultados satisfatórios" (RAPOSO, 2004, p. 311).
Fala-se em cotas quando há reserva de certo número ou percentagem de lugares a pessoas pertencentes a determinado grupo, independentemente dos seus méritos pessoais, classificando-os acima daqueles que acederiam mediante os mecanismos normais de acesso ao lugar. (RAPOSO, 2004, p. 320).

As reservas são sociais e raciais. As primeiras são das vagas que serão ocupadas em razão de critérios como a renda ou a natureza pública da escola de origem; as reservas raciais são as relativas a vagas que serão ocupadas por estudantes negros ou indígenas. Para Duarte (2009), as reservas étnicas e raciais integram as reservas sociais, pois têm por fundamento de existência a exclusão racial ou étnica, que é um fenômeno social, e não a raça em si.

A polêmica em torno da política de cotas para ingresso no ensino superior iniciou-se no meio da década de 1990 e está estritamente relacionada com a cidadania e a luta contra todo tipo de discriminação (BRANDÃO, 2005) Segundo José Jorge de Carvalho (2006), discutir cotas é repensar e avaliar a função social da universidade pública, que deveria formar lideranças que representassem a diversidade étnica e racial do país: brancos, negros e índios nos quadros discente, docente e de pesquisa.

Segundo o juiz federal Oscar Valente Cardoso (2010), a reserva de cotas nas universidades brasileiras é uma farsa para esconder os péssimos resultados das políticas públicas em relação à educação infantil, ao ensino fundamental e médio. Para ele, o problema deve ser resolvido com o aprimoramento das condições da educação infantil e dos ensinos fundamental e médio público. Este é também o entendimento do professor Carlos da Fonseca Brandão (2005), da área de educação.

Em contrapartida, José Jorge de Carvalho (2006) resume os motivos que justificam a legitimidade e a urgência das cotas nas universidades: a) reparação, pois após mais de 300 anos de escravidão a comunidade negra exige uma compensação pela escravidão; b) a cobrança de um direito, pois a Constituição de 1988 assegura um tratamento igual a todos os cidadãos, entre eles o acesso ao ensino gratuito, garantindo uma participação mínima dos negros no ensino superior; c) a presença de negros na universidade enriquecerá a produção de saberes; d) a intensificação da luta antirracista no Brasil. 
Menezes (2001), estudioso do tema, é igualmente favorável à reserva de vagas para ingresso de negros nas universidades públicas, pois, para ele, apenas o sistema de cotas pode garantir aos afrodescendentes artificialmente e em curto prazo a igualdade de oportunidades para o acesso ao ensino superior. Ainda, para Jensen:

Com relação às políticas de cotas para acesso às universidades, estas parecem ser a única modalidade viável de ações com vistas a corrigir, em caráter emergencial, a situação de vulnerabilidade experimentada pelos afrodescendentes, no atual contexto brasileiro, consistente nas dificuldades experimentadas quanto ao acesso à educação superior, e consequentemente, em sua sub-representação nos corpos discentes das instituições do ensino superior. (JENSEN, 2010, p. 252).

Uma questão levantada para rechaçar as cotas é relacionada ao princípio da igualdade de condições de acesso e permanência nas universidades. Muitos afirmam que o sistema de cotas estaria violando o princípio da igualdade, em razão das condições diferenciadas de acesso. Contudo, como observa o professor de direito constitucional Marcos Augusto Maliska, "é inadequado se considerar apenas a resolução de uma prova para todos os candidatos como critério suficiente para dizer que todos estão sob as mesmas condições" (MALISKA, 2009, p. 67).

O artigo 208, inciso V, da Constituição Federal de 1988, tem sido usado para sustentar argumentos contrários à utilização das cotas. Conforme prevê o dispositivo, o acesso aos níveis mais elevados de ensino dá-se segundo a capacidade de cada um e, assim, esses níveis elevados seriam daqueles com as melhores notas nas provas realizadas. A educação é, contudo, um direito social assegurado pela Constituição Federal (artigo 205) e sua concretização depende de ações positivas por parte do Estado (CARDOSO, 2010).

Por meio da Arguição de Descumprimento de Preceito Fundamental 186, pretende-se a declaração de inconstitucionalidade de atos da Universidade de Brasília que instituíram a política de cotas raciais em seus vestibulares, além da extensão da decisão a todos os programas dessa natureza. Na ADPF 186 há a exposição de que o objetivo não é a declaração de inconstitucionalidade das ações afirmativas em geral, as quais possibilitam a inclusão de minorias e o aprimoramento do Estado democrático de direito. Há também o reconhecimento de que o Brasil adota o modelo de Estado social, priorizando pela integração de minorias e a redução das desigualdades, e objetiva deixar claro que não se discute a existência de racismo, preconceito e discriminação na sociedade brasileira, práticas que devem ser banidas, combatidas e punidas.

O texto da ADPF questiona a constitucionalidade da implementação, no Brasil, de ações afirmativas baseadas na raça (política de cotas raciais), utilizando informações de biólogos de que a ciência já teria provado que raças não existem de um ponto de vista genético. Além disso, o texto afirma que, graças à miscigenação, não seria possível determinar quem é negro no país e, por isso, haveria o problema da impossibilidade de definição dos potenciais beneficiários.

Embora biologicamente as raças não possam ser definidas, a questão persiste culturalmente. A defesa de ações afirmativas raciais não está relacionada a uma visão biológica do conceito de raça. Na verdade, cor e raça são frutos de processos sociais que geraram e geram desigualdades sociais específicas, em que as menores chances de mobilidade social dos negros em relação aos não negros são produtos (FERES JÚNIOR; DAFLON; CAMPO, 2010).

Quanto ao problema de identificação dos beneficiários da política, em consequência da miscigenação do povo brasileiro,

[...] o destacado pesquisador da identidade negra no Brasil, Joel Rufino dos Santos, define o negro não como um membro de raça, nem tampouco pela sua localização no espectro da escala de cores humanas. Negro para ele: "[...] é um lugar social instituído por diversas coordenadas: a cor da pele, a cultura popular, a ancestralidade africana, a ascendência escravocrata (remota ou próxima), a pobreza, a atribuição da identidade de negro pelo outro e a assunção dessa identidade por si". (SELL, 2002, p. 61).

Ahyas Siss (2003), estudioso do tema, entende que políticas do Estado direcionadas a determinados grupos minoritários que sofreram e sofrem discriminação, juntamente com políticas universais, são muito úteis para a diminuição dos níveis de desigualdade 
entre brancos e afro-brasileiros, por exemplo, principalmente em uma sociedade excludente como a do Brasil.

O Brasil foi a última nação da América a abolir a escravidão (IBGE). Uma falsa liberdade, pois os recém-libertos foram lançados em uma sociedade preconceituosa. Muitos retornaram às fazendas, recebendo salários baixos (CARVALHO, 2002). Não tiveram oportunidades para seu desenvolvimento dentro do país e ainda eram muito discriminados. Isso não atingiu somente os descendentes diretos dos negros libertos. Ao contrário, essa situação histórica tem consequências atuais, pois se "revela a correlação entre os fatores cor negra e situação econômica desfavorável, o denominado efeito transgeracional da injustiça de origem" (JENSEN, 2010, p. 89). Hoje, no Brasil, ainda é possível ver os reflexos dessa história de desigualdade e exploração. Alguns indicadores referentes a população, família, educação, trabalho e rendimento, que são importantes para retratar de forma resumida a situação social de brancos, negros e pardos, revelam desigualdades em todas as dimensões e áreas geográficas do país.

Daí a necessidade da implementação de programas temporários com a finalidade de alterar essa situação. As políticas sociais compensatórias raciais desempenham importante papel para corrigir as desigualdades historicamente acumuladas, pois promovem igualdade de resultados (SISS, 2003). Segundo Raposo (2004), as ações afirmativas não precisam representar um valor propugnado pela Constituição, bastando que estejam fundadas em um valor constitucionalmente aceitável. Contudo, em relação às cotas não basta isso, pois é necessário que as medidas sejam constitucionalmente desejáveis, passando pelo teste da necessidade, adequação e proporcionalidade:

Apenas superarão o teste da constitucionalidade as medidas de ação positiva que apresentem as seguintes características: a) seja mínima a diferença de mérito entre o membro do coletivo menosprezado que acaba por ser selecionado e o indivíduo que caso contrário o seria; b) existam provas evidentes de discriminação suficientemente relevante; c) os objetivos percentuais fixados sejam flexíveis, de modo a poderem sofrer adaptações, conforme a evolução da situação; d) se verifique a exigida proporcionalidade entre os ganhos obtidos e os custos sociais e jurídicos que implica. Sobre as affirmative actions que não reúnam os citados requisitos pesarão fortes dúvidas de constitucionalidade. (RAPOSO, 2004, p. 332).

A questão da constitucionalidade da política de cotas está estritamente relacionada ao princípio da igualdade. Segundo o professor Humberto Ávila,

A igualdade pode funcionar como regra, prevendo a proibição de tratamento discriminatório; como princípio, instituindo um estado igualitário com o fim a ser promovido; e como postulado, estruturando a aplicação do direito em função de elementos (critério de diferenciação e finalidade da distinção) e da relação entre eles (congruência do critério em razão do fim). (ÁVILA, 2010, p. 152).

José Afonso da Silva (2010) explica que, em razão do princípio da supremacia da Constituição, todas as regras e situações jurídicas devem estar em conformidade com ela, ou seja, as normas do ordenamento jurídico devem ser compatíveis com a norma fundamental para que tenham validade. A incompatibilidade das normas inferiores com a Constituição se manifesta de duas maneiras: as inconstitucionalidades formal e a material. $\mathrm{Na}$ inconstitucionalidade formal, as normas são criadas por autoridades incompetentes ou em desacordo com formalidades ou procedimentos estabelecidos pela Constituição. Já na inconstitucionalidade material, o conteúdo das leis ou atos contraria preceito ou princípio constitucional.

A análise da constitucionalidade da política de cotas raciais não pode ser feita sem a presença do princípio da proporcionalidade e da técnica de ponderação entre princípios. No caso, para a concretização do princípio da igualdade material, o comportamento adequado seria a implementação da política de cotas para negros.

O princípio da proporcionalidade baseia-se na relação entre meio e fim. No direito alemão, o princípio da proporcionalidade foi dividido em três subprincípios: adequação, necessidade e proporcionalidade em sentido estrito. O subprincípio da adequação ou idoneidade exige que a restrição a um direito fundamental atinja um fim constitucionalmente legítimo e consubstancie um meio instrumentalmente adequado à obtenção do fim (PEREIRA, 2007). Acrescenta-se que "a medida será adequada se o 
julgador, no momento da decisão e depois que ela for adotada, verificar que a medida promove o fim" (ÁVILA, 2010, p. 170).

Segundo Ávila, este princípio "se aplica apenas a situações em que há uma relação de causalidade entre dois elementos empiricamente discerníveis, um meio e um fim" (ÁVILA, 2010, p. 163). No caso das cotas, o fim constitucionalmente legítimo é a maior representação dos negros nas universidades e, consequentemente, a redução da discriminação racial e de focos de desigualdade. O meio é o sistema de cotas. Dessa forma, não há dúvidas de que "o meio empregado coopera para materializar o fim buscado" (ÁVILA, 2010, p. 172).

O subprincípio da necessidade tem relação com a exigência de que a medida a ser adotada seja menos lesiva para o direito afetado, guardando relação com o princípio da proibição de excesso. Pelo princípio da necessidade, anote-se que não há outro meio menos oneroso que resulte no fim pretendido. O subprincípio da proporcionalidade em sentido estrito se verifica quando o proveito que se obtém a partir da implementação do fim que justifica a medida restritiva, devendo compensar os sacrifícios que esta acarreta (PEREIRA, 2007).

Com o sistema de cotas, a representação dos negros nas universidades aumentou e as consequências dessa política pública provavelmente acarretarão diminuição de desigualdades, o que compensa eventuais restrições de direitos. Ademais, segundo Brandão (2005), as universidades públicas americanas que utilizaram o sistema de cotas para selecionar seus estudantes argumentam que, além da diversidade étnica, esse sistema gera diversidade cultural entre os alunos, contribuindo para elevar o nível educacional de todos.

Na ADPF 186, o Defensor Público-Geral da União expôs seu posicionamento a favor das cotas raciais e sustentou que as cotas não são excessivas, mas vão ao encontro do princípio da proporcionalidade, pois o percentual reservado é razoável. A maioria das vagas ainda continua à disposição para a disputa de todos e os beneficiários não ficam dispensados de prestar o exame de admissão. Nesta perspectiva, estar-se-ia, pela regra da proporcionalidade, afastando a incidência integral de certos direitos fundamentais em prol de maior representação dos negros na área universitária.
O representante do Ministério Público Federal também se manifestou favoravelmente à política de cotas, afirmando que a proibição de preconceitos de raça, cor, sexo, idade e outras formas de discriminação (CF, art. $3 .^{\circ}$, inciso IV) não pode ser vista como obstáculo à instituição de medidas que favoreçam grupos discriminados, mesmo que estas medidas adotem como fator discriminatório quaisquer destes critérios. Ressaltou que o racismo continua marcante nas relações sociais brasileiras e que há uma super-representação de negros nos presídios e como vítimas de homicídio e violência policial, e pequena ou nenhuma representação de negros em funções mais valorizadas na sociedade, nos cargos de direção e gerência de empresas, nos parlamentos, na magistratura, em profissões como medicina e do direito, por exemplo.

Sendo a educação um direito social, ela tende a reduzir as desigualdades sociais. Mas, para isso, é necessário democratizar o acesso à educação, principalmente ao ensino superior. Em relação à criação de cotas pelas universidades, o artigo 207 da Constituição da República e a Lei de Diretrizes e Bases da Educação Nacional (Lei 9.394/1996), em seu artigo 53, prescreve a autonomia didático-científica das universidades, ou seja, uma ampla margem de exercício tanto para a definição das vagas a serem preenchidas, quanto para os critérios de seleção. E nessa margem de exercício encontra-se a instituição do sistema de cotas.

Diversas universidades do Brasil têm adotado a política de cotas raciais nos vestibulares, "fazendo-o por ato administrativo, uma vez que o Congresso Nacional ainda não legislou esta modalidade de ingresso no ensino superior, a despeito de existirem projetos de lei em tramitação" (CARMONA, 2010, p. 526). Não tem amparo a alegação da inconstitucionalidade considerando-se a criação de política de cotas por meio de instrumento infralegal, pois não se encontra na Constituição reserva legal à forma de acesso ao ensino superior público. De modo diametralmente oposto a essa alegação, o artigo 207 prescreve a autonomia didático-científica e administrativa das universidades, tendo estas legitimidade para estabelecer sistemas de cotas, desde que, obviamente, não violem outros preceitos constitucionais.

Mesmo para aqueles que entendem que as políticas de cotas raciais são criadas pelas universidades 
com permissão de normas infralegais inconstitucionais, é importante fazer menção à lição de Humberto Ávila:

No caso do controle concentrado de constitucionalidade, o Supremo Tribunal Federal e o Tribunal Constitucional Alemão têm analisado atos administrativos ou normativos editados em desconformidade com a Constituição. Apesar disso, os tribunais têm proferido várias decisões no sentido de manter os efeitos decorrentes desses atos por entender que manter os efeitos decorrentes desses atos "promove mais" o ordenamento constitucional que não mantê-los. Nesse sentido, a afirmação de Gusy: A manutenção de leis inconstitucionais até a nova regulação legislativa não é apenas praticamente necessária, mas também constitucionalmente obrigatória: ela é "mais próxima da Constituição’. (ÁVILA, 2010, p. 131).

O fim a que se pretende é a diminuição da discriminação racial e a inclusão efetiva dos afro-brasileiros na sociedade, primeiramente com maior representação nas universidades. Esta maior representação será alcançada por meio do acesso facilitado, tendo como instrumento o sistema de cotas raciais, o que, além de não afrontar a Constituição Federal, consubstancia-se em importante instrumento na busca dos objetivos fundamentais da República Federativa do Brasil (CF, art. 3. ${ }^{\circ}$ ), dentre eles a construção de uma sociedade livre, justa e solidária (inciso I), a erradicação da pobreza e da marginalização e a redução das desigualdades sociais e regionais (inciso III) e a promoção do bem de todos, sem preconceitos de origem, raça, sexo, cor, idade e quaisquer outras formas de discriminação (inciso IV).

\section{Conclusão}

A questão que envolve a constitucionalidade da política de cotas raciais está estritamente relacionada ao princípio da igualdade. A igualdade material possibilita a implantação de ações afirmativas que abrangem políticas temporárias, públicas ou privadas, voltadas a grupos que foram e ainda são marginalizados. A reserva de vagas enquadra-se à situação brasileira de exclusão etnorracial, o que justifica a implantação dessa política pública.

A escravidão já ocorreu, não há como punir os responsáveis por ela e muito menos indenizar especificamente os que foram escravos. No entanto, é possível reduzir e combater a discriminação racial e compensar a desvantagem dos negros acumulada historicamente para viabilizar a efetivação de três dos quatro objetivos fundamentais da República Federativa do Brasil (CF, art. 3. $\left.{ }^{\circ}\right)$ : a construção de uma sociedade livre, justa e solidária (inciso I), a erradicação da pobreza e da marginalização e a redução das desigualdades sociais e regionais (inciso III) e a promoção do bem de todos, sem preconceitos de origem, raça, sexo, cor, idade e quaisquer outras formas de discriminação (inciso IV).

A política de cotas raciais não viola a Constituição. É materialmente constitucional e está em consonância com o postulado da proporcionalidade. Afinal, a igualdade não pode ser vista como princípio estático, puramente formal, mas tem de funcionar como regra, princípio e postulado: ao mesmo tempo em que se devem proibir tratamentos discriminatórios arbitrários, deve-se admitir e incentivar a promoção de certas discriminações positivas (a fim de instituir um estado igualitário) e, ainda, estruturar a aplicação do direito e o ideal de justiça.

\section{Referências}

ÁVILA, Humberto. Teoria dos Princípios: da definição à aplicação dos princípios jurídicos. 11. ed. São Paulo: Malheiros, 2010.

BERTÚLIO, Dora Lúcia de Lima. Racismo e Desigualdade racial no Brasil. In: DUARTE, E. P; BERTÚLIO, D. L. L.; SILVA, P. V. B. (Coord.). Cotas raciais no ensino superior. Curitiba: Juruá, 2009.

BRANDÃO, Carlos da Fonseca. As cotas na Universidade Pública Brasileira: será este o caminho? Campinas: Autores Associados, 2005.

BRASIL. Constituição (1988). Constituição da República Federativa do Brasil: promulgada em 5 de outubro de 1988. Disponível em: <http://www.planalto.gov.br/ccivil_03/ constituicao/constitui\%C3\%A7ao.htm>. Acesso em: 06 set. 2011.

BRASIL. Lei $\mathbf{n}^{\mathbf{0}}$ 9.394, de 20 de dezembro de 1996. Estabelece as diretrizes e bases da educação nacional. Disponível em: < http://www.planalto.gov.br/ccivil_03/leis/ L9394.htm>. Acesso em: 07 set. 2011.

BRASIL. Lei n. 12.288, de 20 de julho de 2010. Institui o Estatuto da Igualdade Racial; altera as Leis $\mathrm{n}^{\mathrm{os}} 7.716$, de 5 de janeiro de 1989, 9.029, de 13 de abril de 1995, 7.347, de 24 de julho de 1985, e 10.778, de 24 de novembro de 2003. 
Disponível em: <http://www.planalto.gov.br/ccivil_03/_ Ato2007-2010/2010/Lei/L12288.htm>. Acesso em: 27 out. 2010.

BRASIL. Projeto de Lei $\mathbf{n}^{\circ} \mathbf{3 . 1 9 8}$, de 2000. Institui o Estatuto da Igualdade Racial, em defesa dos que sofrem preconceito ou discriminação em função de sua etnia, raça e/ ou cor, e dá outras providências. Brasília, 2003. Disponível em:<http://bvsms.saude.gov.br/bvs/publicacoes/pop_negra/ estatuto_racial.pdf $>$. Acesso em: 17 set. 2011.

CARDOSO, Oscar Valente. As ações afirmativas e a inefetividade do direito à educação. In: HIROSE, Tadaaqui; NETO, João Pedro Gebran (Org.). Curso Modular de Direito Constitucional. São Paulo: Conceito Editorial, 2010, p.171.

CARMONA, Rafael Selau. Análise do sistema de cotas no vestibular da Universidade Federal de Santa Catarina. In: HIROSE, Tadaaqui; NETO, João Pedro Gebran (Org.). Curso Modular de Direito Constitucional. São Paulo: Conceito Editorial, 2010.

CARVALHO, José Jorge de. Inclusão Étnica e Racial no Brasil: a questão das cotas no ensino superior. 2.ed. São Paulo: Attar Editorial, 2006.

CARVALHO, José Murilo de. Cidadania no Brasil. O longo Caminho. 3. ed. Rio de Janeiro: Civilização Brasileira, 2002.

DUARTE, Evandro C. Piza. Princípio da Isonomia e Critérios para a discriminação positiva nos programas de ação afirmativa para negros (afrodescendentes) no ensino superior. In: DUARTE, E.P; BERTÚLIO, D.L.L; SILVA, P.V.B.(Coord.). Cotas raciais no ensino superior. Curitiba: Juruá, 2009.

DWORKIN, Ronald. Uma questão de princípio. Tradução de Luís Carlos Borges. São Paulo: Martins Fontes, 2000.

FERES JÚNIOR, João; DAFLON, Verônica Toste; CAMPO, Luiz Augusto. Cotas no STF. Insight Inteligência, ano XII n. 49, p. 124-136, abril/maio/jun 2010. Disponível em: <http:// www.insightnet.com.br/inteligencia/49/>. Acesso em: 28 out. 2010.

GARCIA, Maria Glória F.P.D. Estudos sobre o princípio da igualdade. Coimbra: Almedina, 2005.

GOMES, Joaquim B. Barbosa. Ação afirmativa \& Princípio Constitucional da Igualdade. O Direito como instrumento de transformação social. A experiência dos EUA. Rio de Janeiro: Renovar, 2001.

INSTITUTO BRASILEIRO DE GEOGRAFIA E ESTATÍSTICA - IBGE. Ontem e hoje, o negro no Brasil. Disponível em: <http:/www.ibge.gov.br/ibgeteen/datas/ discriminacao/ontemhoje.html $>$. Acesso em: 25 jul.2011.

Síntese de Indicadores Sociais: Uma análise das condições de vida da população brasileira. Disponível em: <http://www.ibge.gov.br/home/estatistica/ populacao/condicaodevida/indicadoresminimos/ sinteseindicsociais2010/SIS_2010.pdf $>$. Acesso em: 01 set. 2010.

JENSEN, Geziela. Políticas de cotas raciais em universidades brasileiras: entre a legitimidade e a eficácia. Curitiba: Juruá, 2010.

MALISKA, Marcus Augusto. Análise da constitucionalidade das coras para negros em Universidades Públicas. In: DUARTE, E. P.; BERTÚliO, D. L. L.; SILVA, P. V. B.(Coord.). Cotas raciais no ensino superior. Curitiba: Juruá, 2009.

MELLO, Celso Antônio Bandeira de. O Conteúdo Jurídico do Princípio da Igualdade. 3. ed. São Paulo: Malheiros, 2004.

MENEZES, Paulo Lucena de. A ação afirmativa (Affirmative action) no direito norte-americano. São Paulo: Editora Revista dos Tribunais, 2001.

MOEHLECKE, Sabrina. Ação Afirmativa no Ensino Superior: entre a excelência e a justiça racial. Revista de Ciência da Educação. São Paulo, vol. 25, n.88, p. 757-776, out. 2004

PAULA, Alexandre Sturion de. Ação afirmativa: instrumento de cidadania ou discriminação reversa? Semina, Londrina, vol.25, p. 3-18, set. 2004.

PEREGALLI, Enrique. Escravidão no Brasil. 3. ed. Global: São Paulo, 1988.

PEREIRA, Jane Reis Gonçalves. Os Imperativos de Razoabilidade e de Proporcionalidade. In: BARROSO, Luís Roberto (Org.). A Reconstrução Democrática do Direito Público no Brasil. Rio de Janeiro: Renovar, 2007.

RAPOSO, Vera Lúcia Carapeto. O poder de Eva: O princípio da igualdade no âmbito dos direito políticos; problemas suscitados pela discriminação positiva. Coimbra: Almedina, 2004.

RIOS, Roger Raupp. Ações afirmativas no Direito Constitucional brasileiro: reflexões a partir do debate constitucional estadunidense. In: SCHILLIN, Maria Luiza Bernardi Fiori (Org.). Direito Constitucional - módulo V. O direito Constitucional da Igualdade e o direito da antidiscriminação. Disponível em: <http://www.trf4.jus.br/ trf4/upload/arquivos/emagis_atividades/ccp5_roger_raupp rios.pdf $>$. Acesso em: 20 jun. 2011.

SELL, Sandro Cesar. Ação Afirmativa e democracia racial: uma introdução ao debate no Brasil. Florianópolis: Fundação Boiteux, 2002.

SILVA FILHO, Antônio Leandro da. A judicialização do político: ações judiciais propostas contra o plano de metas de inclusão racial e social da UTFPR. In: DUARTE, E. P.; BERTÚllO, D. L. L; SILVA, P.V.B.(Coord.). Cotas raciais no ensino superior: entre o jurídico e o político. Curitiba: Juruá, 2009. 
SILVA, José Afonso da. Curso de Direito Constitucional Positivo. 33. ed. rev. e atual. São Paulo: Malheiros, 2010.

SILVÉRIO, Valter Roberto. Affirmative action in the United States and India: a comparative perspective. Tempo social [online], São Paulo, v.18, n.2, p. 307-312, nov. 2006. Disponível em: <http://dx.doi.org/10.1590/S010320702006000200017>. Acesso em: 14 abr. 2011. Resenha.

SISS, Ahyas. Afro-brasileiros, cotas e ação afirmativa: razões históricas. Rio de Janeiro: Quartet; Niterói: PENESB, 2003.

TOLEDO, Roberto Pompeu de. À sombra da escravidão. Veja, São Paulo, ano 29, n. 20, ed. 1444, p. 52-65, 15 maio. 1996. 